\title{
$\mathrm{PH} 102$ accualidad
}

\section{Vides Creuades persigue el entendimiento entre culturas a través de relatos ciudadanos}

\begin{abstract}
Es un proyecto cultural comunitario que se lleva a cabo en el barrio de Orriols (Valencia) bajo la coordinación de CARPE y la colaboración de la Asociación Orriols Convive. A través de una metodología experimental, Vides Creuades visibiliza, conecta y construye relatos que habitan en los barrios multiculturales con el objetivo de fomentar el sentimiento de pertenencia, establecer vínculos comunitarios y contruir identidad de un lugar. Con dos ediciones de experiencia, a finales del año 2020, el proyecto ganaba el premio de Innovación Social y Urbana ciudad de València.
\end{abstract}

Irene Reig Alberola | Co-fundadora del colectivo CARPE

URL de la contribución <http://www.iaph.es/revistaph/index.php/revistaph/article/view/4811>

Vides Creuades se inicia tras años de realización de procesos de participación ciudadana y las reflexiones que éstos despertaron en CARPE, un estudio de diseño que trabaja desde un enfoque experimental y colaborativo en arquitectura, placemaking e innovación ciudadana. Cada vez se hacía más presente la falta de inclusión de relatos diversos en espacios de participación urbana en territorios que acogen de forma frecuente movimientos migratorios. Ante esta situación, Vides Creuades entra en juego y propone una metodología que trabaja por círculos de confianza para afrontar la falta de sentimiento de pertenencia en ciertos barrios multiculturales, necesaria para poder establecer vínculos comunitarios y reconocerse como ciudadanía capaz de construir la identidad del lugar que habita.

Hasta la fecha, se han desarrollado dos ediciones, 2019 y 2020, en el barrio de Orriols, por ser precisamente uno de los barrios de la ciudad de València con mayor porcentaje de población migrante, pero también por tener un importante tejido asociativo formado por entidades que trabajan por el fomento de la convivencia y la interculturalidad a través del empoderamiento ciudadano.

Para asegurar una visión completa del territorio, se trabaja en colaboración con el proyecto comunitario Orriols Convive, para que la selección de protagonistas en cada edición permita mantener la igualdad en la representatividad de hombres y mujeres, invertir el porcentaje de visi- bilidad de gente local y extranjera, visibilizar etnias con lenguas no locales por estar en una situación de vulnerabilidad mayor y mostrar, a través de visiones intergeneracionales, las olas migratorias que ha acogido el barrio.

Una vez localizados los protagonistas, el proyecto se pone en marcha con la sencilla acción de recopilación de historias personales de las que se pueda comprender los espacios físicos, digitales y emocionales que soportan las vidas de los barrios. Estos datos se geolocalizan y se ordenan para poder diseñar la siguiente fase del proyecto, pero también se disponen en un archivo

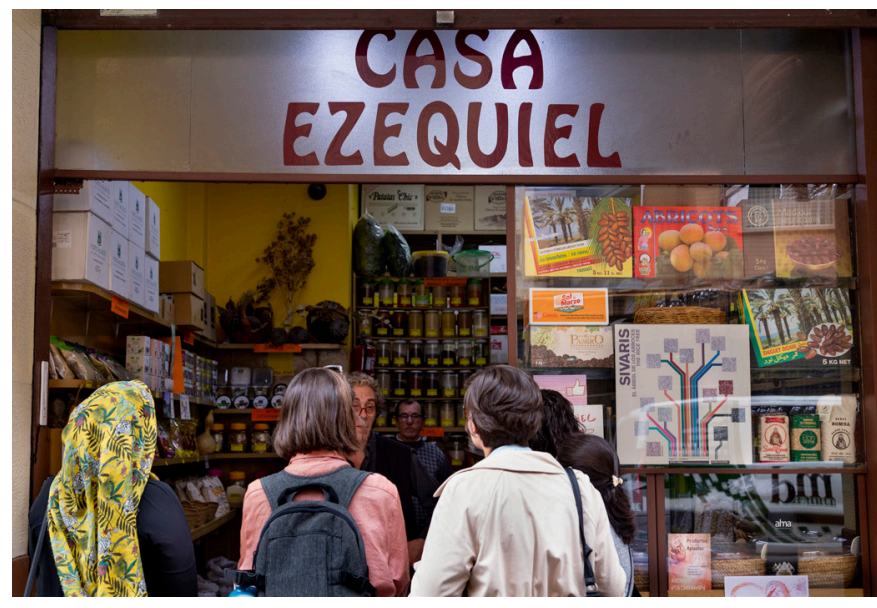

Ruta urbana realizada con las mujeres protagonistas de la edición 2019: Hawa Maria y Marta | foto Vides Creuades, fuente de todas las imágenes 


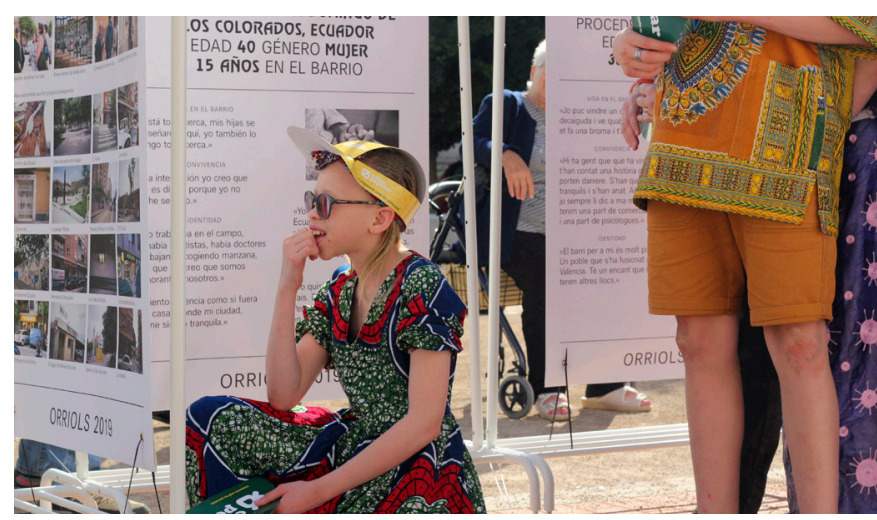

Acción pública durante la Semana Intercultural de Orriols, Valencia (2019)

abierto para que puedan ser empleados en la realización de diagnósticos urbanos, en diseño de servicios comunitarios o en estudios sociológicos. En el caso de Vides Creuades, se emplean para diseñar rutas urbanas donde en pequeños grupos se puedan realizar visitas a aquellos espacios de referencia de cada protagonista. El intercambio en un grupo acotado permite conocer de manera cercana y afectiva otras vidas hasta ahora entre ellas no conocidas.

Como acción final, el proyecto plantea traspasar de la esfera digital a la presencial, abrirse y dar a conocer el trabajo realizado en cada edición. De forma conjunta con agentes sociales y con participantes, se muestra en el espacio público las historias y los deseos de las personas que construyen la identidad del barrio. Por medio de acciones urbanas, se quiere exponer el ámbito personal de un territorio multicultural para fomentar el entendimiento entre culturas y el acercamiento de visiones desde una perspectiva individual y, por tanto, excepcional.

La primera edición de Vides Creuades se desarrolla dentro del programa Emergents 2018, promovido por la Concejalía de Juventud del Ayuntamiento de València y la Universitat de València. Durante tres meses, se pone a prueba la metodología con seis personas protagonistas de diferentes orígenes, niveles económicos, educativos y generacionales. Aún sin espacio digital, se consigue desarrollar un mapa conceptual de espacios físicos y de intereses que vinculan a las personas participantes. La gran acogida de la exposición demuestra la capacidad de los proyectos culturales comunitarios para movilizar y

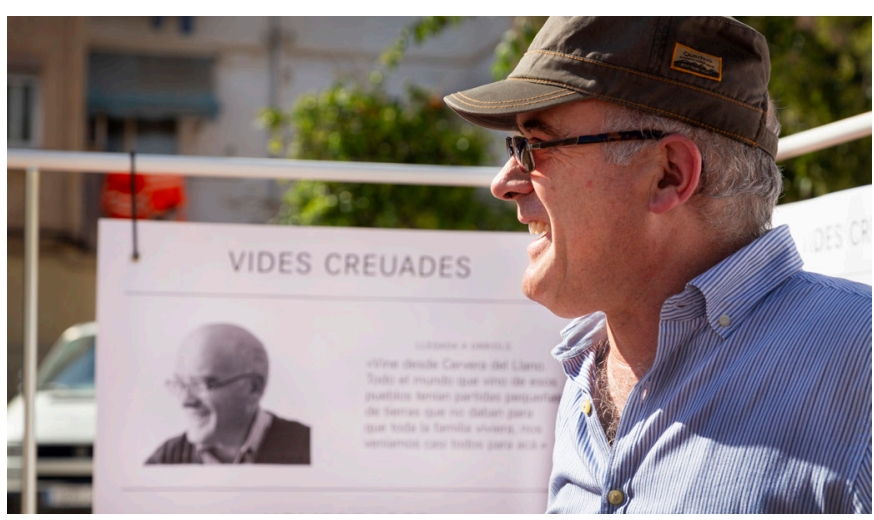

trabajar la participación desde un enfoque cercano, colaborativo y situado.

La segunda edición se desarrolla dentro del programa europeo Designscapes, promovido por un consorcio de entidades sociales y educativas. Además de la ampliación de protagonistas, se consolida el proyecto a través de un espacio digital, un mapa de relatos y un archivo que organiza el contenido generado hasta la fecha. Debido a la crisis sanitaria COVID-19 se reformularon las actividades colectivas y la acción pública, planteando actividades para conocer el territorio y a sus personas en situación de distanciamiento social.

Tras dos años, Vides Creuades ha congregado a un equipo multidisciplinar y multisectorial que busca nuevos horizontes en los que poder colaborar y mostrar los relatos como herramienta para diseñar proyectos de innovación social, acción urbana, datos ciudadanos, o inserción social. Hasta la fecha han formado parte el arquitecto Víctor Soriano, la documentalista Ángela Jurado, los diseñadores Ivan Santana y Diego March y la plataforma Grigri Projects

A finales de 2020, teníamos noticia de que el proyecto Vides Creuades resultaba ganador de la $5 .^{a}$ edición de los Premios a la Innovación Social y Urbana ciudad de València concedidos desde el Servicio de Innovación del Ayuntamiento de esta ciudad. Una edición orientada al marco estratégico Missions València 2030 en las categorías Ciudad Saludable, Ciudad Sostenible y Ciudad Compartida. 